\title{
Variation in Definition of Prolonged Mechanical Ventilation
}

\author{
Louise Rose RN PhD, Michael McGinlay MBBS, Reshma Amin MD, Karen EA Burns MD, \\ Bronwen Connolly PhD, Nicholas Hart PhD, Philippe Jouvet PhD, Sherri Katz MD, \\ David Leasa MD, Cathy Mawdsley MScN, Danny F McAuley PhD, Marcus J Schultz PhD, \\ and Bronagh Blackwood $\mathrm{PhD}$
}

\author{
Introduction \\ Review Methods \\ Study Characteristics \\ Definitions of Prolonged Mechanical Ventilation \\ Rationales for Cohort Terms \\ Reported Outcomes \\ Discussion \\ Strengths and Limitations \\ Summary
}

Consistency of definitional criteria for terminology applied to describe subject cohorts receiving mechanical ventilation within ICU and post-acute care settings is important for understanding prevalence, risk stratification, effectiveness of interventions, and projections for resource allocation. Our objective was to quantify the application and definition of terms for prolonged mechanical ventilation. We conducted a scoping review of studies (all designs except single-case study) reporting a study population (adult and pediatric) using the term prolonged mechanical ventilation or a synonym. We screened 5,331 references, reviewed 539 full-text references, and excluded 120. Of the 419 studies (representing 38 countries) meeting inclusion criteria, $297(71 \%)$ reported data on a heterogeneous subject cohort, and $66(16 \%)$ included surgical subjects only (46 of those $66,70 \%$ cardiac surgery). Other studies described COPD $(16,4 \%)$, trauma $(22,5 \%)$, neuromuscular $(17$, $4 \%)$, and sepsis $(1,0.2 \%)$ cohorts. A total of 741 terms were used to refer to the 419 study cohorts. The most common terms were: prolonged mechanical ventilation $(253,60 \%)$, admission to specialized unit $(107,26 \%)$, and long-term mechanical ventilation $(79,19 \%)$. Some authors $(282,67 \%)$ defined their cohorts based on duration of mechanical ventilation, with 154 studies $(55 \%)$ using this as the sole criterion. We identified 37 different durations of ventilation ranging from $5 \mathrm{~h}$ to $1 \mathrm{y}$, with $>21 \mathrm{~d}$ being the most common ( 28 of $282,7 \%$ ). For studies describing a surgical cohort, minimum ventilation duration required for inclusion was $\geq 24 \mathrm{~h}$ for 20 of 66 studies $(30 \%)$. More than half of all studies $(237,57 \%)$ did not provide a reason/rationale for definitional criteria used, with only 28 studies (7\%) referring to a consensus definition. We conclude that substantial variation exists in the terminology and definitional criteria for cohorts of subjects receiving prolonged mechanical ventilation. Standardization of terminology and definitional criteria is required for study data to be maximally informative. Key words: prolonged mechanical ventilation; intensive care; chronic critical illness; long-term mechanical ventilation; scoping review. [Respir Care 2017;62(10):1324-1332. (C) 2017 Daedalus Enterprises] 


\section{Introduction}

Better understanding of the relationship between the duration of mechanical ventilation and important patient outcomes, such as weaning success and mortality, may be useful to guide discussions of prognosis with patients and their families, facilitate clinical decision making, and set goals of care. ${ }^{1,2}$ Many studies have attempted to identify predictors of prolonged mechanical ventilation (PMV) ${ }^{3-5}$ as well as development of mortality risk prediction models for patients requiring $21^{6}$ and $14 \mathrm{~d}$ of mechanical ventilation. ${ }^{7}$ Understanding predictors of PMV and outcomes of these patients may allow risk stratification enabling targeted and preemptive interventions designed to reduce risk. An understanding of projected PMV prevalence can be used to guide decisions related to resource allocation by organizations and health-care systems.

Although a 2005 consensus conference led by the National Association for Medical Direction of Respiratory Care (NAMDRC) defined PMV as mechanical ventilation for $\geq 21$ consecutive days, for $\geq 6 \mathrm{~h} / \mathrm{d}$, of invasive (via endotracheal tube or tracheostomy) and/or noninvasive (fa$\mathrm{cial} /$ nasal interface) methods of delivery, ${ }^{8}$ variable definitions have been used by study authors. Furthermore, studies using different definitional criteria may be used to summarize prevalence and outcomes. ${ }^{9}$ For example, a commonly cited administrative database study of the predicted prevalence of PMV in the United States used a definition of $\geq 96 \mathrm{~h}^{10}$ because this corresponds to the International Classification of Diseases (ICD) code 96.72 and therefore is easily identified within these databases. These authors refer to the study cohort as requiring prolonged acute me-

Dr Rose is affiliated with the Department of Critical Care Medicine, Sunnybrook Health Sciences Centre; the Lawrence S Bloomberg Faculty of Nursing and the Interdepartmental Division of Critical Care Medicine, University of Toronto; and the Provincial Centre of Weaning Excellence, Toronto East General Hospital, Toronto, Ontario, Canada. Dr McGinlay is affiliated with Royal Victoria Hospital, Belfast, Northern Ireland. Dr Amin is affiliated with SickKids Hospital and the Division of Respirology, University of Toronto, Toronto, Ontario, Canada. Dr Burns is affiliated with Saint Michael's Hospital; the Li Ka Shing Knowledge Institute; and the Interdepartmental Division of Critical Care Medicine, University of Toronto, Toronto, Ontario, Canada. Dr Connolly is affiliated with the Lane Fox Respiratory Unit, St Thomas's Hospital, Guy's and St Thomas's NHS Foundation Trust, London, United Kingdom. Dr Hart is affiliated with the Lane Fox Respiratory Unit, St Thomas's Hospital, Guy's and St Thomas's NHS Foundation Trust, and King's College London, London, United Kingdom. Dr Jouvet is affiliated with the Pediatric Intensive Care Unit, Department of Pediatrics, Sainte-Justine Hospital, and the University of Montreal, Montreal, Quebec, Canada. Dr Katz is affiliated with the Department of Respirology, Children's Hospital of Eastern Ontario, and the CHEO Research Institute, Faculty of Medicine, University of Ottawa, Ottawa, Ontario, Canada. Dr Leasa is affiliated with the Critical Care Western and London Health Sciences chanical ventilation. Other United States studies reporting prevalence and outcomes use other definitions to describe PMV. ${ }^{6,11}$ The use of variable and inconsistent definitions results in widely variable estimates of PMV prevalence, inconsistent identification of independent predictors for its occurrence, differences in estimates of treatment effects, and inaccurate estimation of patient outcomes to inform prognosis discussions and decisions to continue life-sustaining therapy. Furthermore, variable and inconsistent reporting limits comparisons across studies and precludes pooling of data for meta-analyses. ${ }^{12}$

To answer the NAMDRC $2005^{8}$ call for further research to better understand which definitions of PMV are commonly used, to raise awareness related to definitional inconsistency among clinicians, researchers, and other key stakeholders, and to drive consensus for a standardized definition for PMV, we conducted a scoping review to quantify how PMV and its synonyms are defined in the literature.

\section{Review Methods}

We included studies that described the study population (adult and pediatric) using terms such as prolonged mechanical ventilation, prolonged ventilation, prolonged invasive ventilation, prolonged wean, or difficult to wean in the paper's title or abstract or described a study population admitted to a specialized weaning facility, longterm acute care hospital or respiratory unit, and receiving mechanical ventilation. Search terms were developed in consultation with an experienced information specialist. We included all study designs, including observational studies, randomized controlled trials, before-

Centre and Western University, London, Ontario, Canada. Ms Mawdsley is affiliated with the Critical Care Western and London Health Sciences Centre, London, Ontario, Canada. Dr McAuley is affiliated with Royal Victoria Hospital and the Centre for Experimental Medicine, Queen's University, Belfast, Northern Ireland. Dr Schultz is affiliated with the Laboratory of Experimental Intensive Care and Anesthesiology, Academic Medical Center, University of Amsterdam, Amsterdam-Zuidoost, The Netherlands. Dr Blackwood is affiliated with the Centre for Experimental Medicine, Queen's University, Belfast, Northern Ireland.

This study was funded by a Knowledge Synthesis grant from the Canadian Institutes of Health Research. The authors have disclosed no conflicts of interest.

Dr Rose presented a version of this work at the European Society of Intensive Care Medicine Annual Congress, held October 1-5, 2016, in Milan, Italy

Correspondence: Louise Rose RN PhD, Lawrence S Bloomberg Faculty of Nursing, University of Toronto, 155 College Street, Toronto, Ontario M5T IP8, Canada. E-mail: louise.rose@utoronto.ca.

DOI: $10.4187 /$ respcare. 05485 
and-after studies, database studies, surveys, and qualitative studies. We excluded studies describing a long-term mechanical ventilation population defined as subjects with minimal to zero expectation of weaning because we anticipated that these subjects would be receiving care in a long-term care facility and thus not representative of patients receiving ventilation in an acute care setting. We also excluded studies describing subject cohorts receiving mechanical ventilation at home. We excluded single-case reports, commentaries, editorials, reviews, opinion papers, and, for pragmatic reasons, studies reported in languages other than English.

We searched the following electronic databases from 1980 to March 2013: Cochrane, MEDLINE, CINAHL, Embase, LILACS, and the Web of Science and Conference Proceedings.

Using a predesigned screening tool, 2 authors (LR and $\mathrm{MM})$ independently examined study titles and abstracts to identify eligible studies. Full-text articles considered potentially relevant by either author were obtained and examined for eligibility. Disagreements were resolved through thirdauthor (DM) discussion. Two authors in pairs independently extracted study data using a standardized form, and all data extraction was checked for accuracy by a third author (LR). We extracted data on the country or countries where the study was performed, type of care venue, age range and diagnostic categories of subjects, terms used to describe the cohort, definitional criteria for the terms used, and reasons provided for the definitional criteria used. We also extracted reported outcomes to examine types and variability in studies of this patient population. Data extractors were not blinded to study citations.

We generated summary tables reporting counts and proportions of study and cohort characteristics, terms used to describe the cohort, definitional criteria, and study outcomes. Descriptive statistics were generated using SPSS 23 (IBM, Armonk, New York).

\section{Study Characteristics}

We screened 5,331 references and identified 539 references for full text review. We excluded 120 references for reasons shown in Figure 1. Of the 419 studies that met our inclusion criteria, $363(86.6 \%)$ were conducted in a single care venue type (most commonly ICU), 30 (7.2\%) were conducted in multiple care venue types, 18 (4.3\%) were database studies, and $9(2.1 \%)$ were surveys. Of the 419 studies, $366(87.4 \%)$ included adults only, 43 (10.3\%) were pediatric only, $10(2.4 \%)$ included adult and pediatric subjects, and $2(0.5 \%)$ reported data on pediatric and neonate subjects. Studies represented cohorts from 38 countries, most commonly the United States $(187,44 \%)$ (Table 1). Most studies $(297,70.9 \%)$ reported data on heterogeneous subject cohorts, and $66(15.8 \%)$ studies reported data on

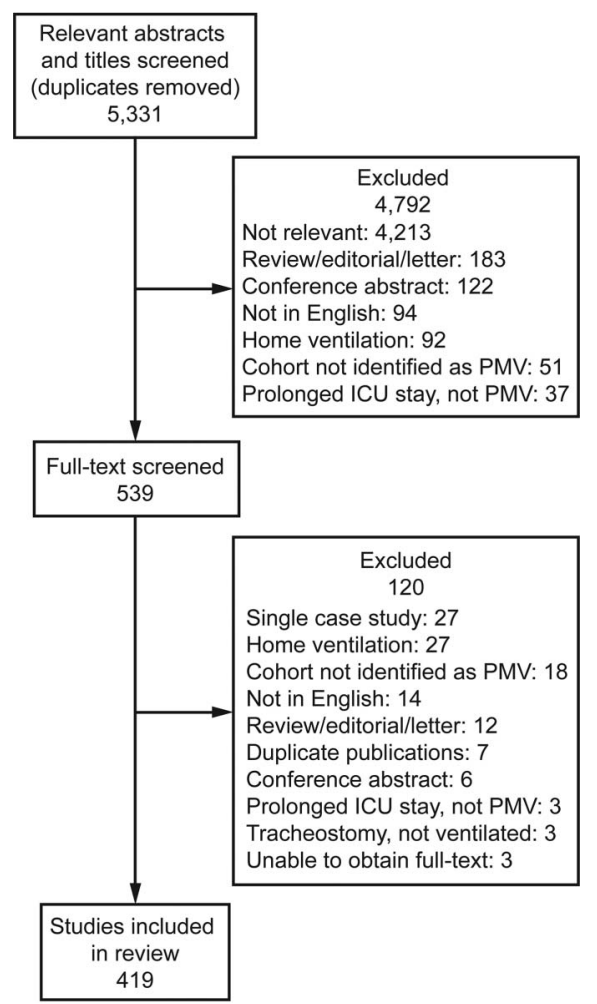

Fig. 1. Flow chart. PMV = prolonged mechanical ventilation.

surgical patients only (46 of those $66,69.7 \%$ cardiac surgery). Other studies described subjects with COPD (16, $3.8 \%$ ); trauma, including burns, spinal cord injury, and acute brain injury $(22,5.3 \%)$; neuromuscular disorders $(17,4.1 \%)$; and sepsis $(1,0.2 \%)$ cohorts.

\section{Definitions of Prolonged Mechanical Ventilation}

A total of 741 terms were used to refer to the 419 study cohorts. The most common terms used were: PMV (253, $34.1 \%)$, admission to a specialized unit (107, 14.4\%), and long-term mechanical ventilation $(79,10.7 \%)$; chronic critical illness was a term used by 33 studies (4.5\%) (Table 2 ). The proportions of studies using the terms PMV and longterm mechanical ventilation were similar in adult-only and pediatric-only studies. No pediatric cohorts were defined using the term chronic critical illness, and only $2(2.8 \%)$ were defined based on unit admission criteria. Table 3 demonstrates that the top 5 terms (PMV, unit admission criteria, long-term mechanical ventilation, tracheostomy, and ventilator dependence) remained consistent over time, although use of the terms long-term mechanical ventilation and ventilator dependence declined after 2003 and 1999, respectively. Most studies (282 of 419, 67.3\%) used the duration of mechanical ventilation as one of their definitional criteria, with over half of these studies (154 of $282,54.6 \%$ ) using this as the only defining criterion. Of 
Table 1. Characteristics of Institutions Participating in Included Studies

\begin{tabular}{|c|c|}
\hline Characteristics & No. $(\%)$ \\
\hline \multicolumn{2}{|l|}{ Region (no. $=419$ ) } \\
\hline United States & $187(44.6)$ \\
\hline Europe* & $98(23.4)$ \\
\hline Asia $\dagger$ & $60(14.3)$ \\
\hline United Kingdom & $23(5.5)$ \\
\hline South America & $15(3.6)$ \\
\hline Canada & $11(2.6)$ \\
\hline Middle East $§$ & $10(2.4)$ \\
\hline Australia & $10(2.4)$ \\
\hline Africa\| & $3(0.7)$ \\
\hline Multiple countries & $2(0.5)$ \\
\hline \multicolumn{2}{|l|}{ Population $($ no. $=419)$} \\
\hline Adult only & $366(87.4)$ \\
\hline Pediatric only & $43(10.3)$ \\
\hline Both adult and pediatric & $10(2.4)$ \\
\hline \multicolumn{2}{|l|}{ Care venue $($ no. $=430) \mathrm{I}$} \\
\hline $\mathrm{ICU}$ & $273(63.5)$ \\
\hline $\begin{array}{l}\text { Respiratory intermediate care unit or HDU } \\
\text { (step-up/down unit) }\end{array}$ & $47(10.9)$ \\
\hline Weaning center, external referral or in-house & $47(10.9)$ \\
\hline $\begin{array}{l}\text { Long-term care/chronic ventilation or } \\
\text { rehabilitation facility }\end{array}$ & $32(7.4)$ \\
\hline LTAC (United States) & 17 (3.9) \\
\hline Ward & $5(1.2)$ \\
\hline Home & $5(1.2)$ \\
\hline Other** & $4(0.9)$ \\
\hline \multicolumn{2}{|l|}{ Number of units $($ no. $=376) \dagger \dagger$} \\
\hline Single unit & $312(83.0)$ \\
\hline 2 units & $17(4.5)$ \\
\hline 3 units & $10(2.7)$ \\
\hline 4 units & $17(4.5)$ \\
\hline$\geq 5$ units & $19(5.1)$ \\
\hline \multicolumn{2}{|c|}{ 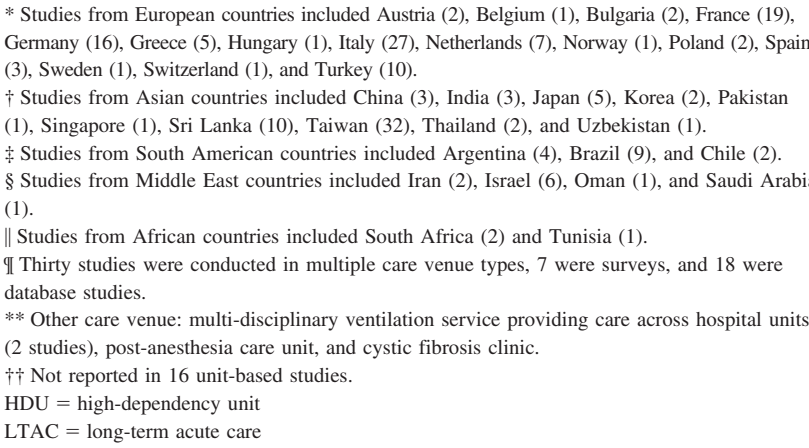 } \\
\hline
\end{tabular}

the 253 studies using the term PMV to describe their cohort, $182(71.9 \%)$ included the duration of mechanical ventilation as a definitional criterion. In total, we identified 37 different durations of ventilation. This variability remained (range $\geq 72 \mathrm{~h}$ to $>3$ months) when including only multicenter studies of $>5$ units, database, or survey studies. Of the 419 studies, $53(12.6 \%)$ used $\geq 21 \mathrm{~d}$
Table 2. Terms Used to Describe Study Cohorts

\begin{tabular}{lccc}
\hline \hline \multicolumn{1}{c}{ Descriptor* } & $\begin{array}{c}\text { Overall } \\
\text { (no. }=741)\end{array}$ & $\begin{array}{c}\text { Adult Only } \\
\text { (no. }=654)\end{array}$ & $\begin{array}{c}\text { Pediatric } \\
\text { Only } \\
\text { (no. = 71) }\end{array}$ \\
\hline Prolonged mechanical ventilation & $253(34.1)$ & $225(34.4)$ & $23(32.4)$ \\
Admission criteria of specialized unit & $107(14.4)$ & $105(16.1)$ & $2(2.8)$ \\
Long-term mechanical ventilation & $79(10.7)$ & $69(10.6)$ & $7(9.9)$ \\
Tracheostomy & $67(9.0)$ & $52(8.0)$ & $13(18.3)$ \\
Ventilator-dependent & $53(7.2)$ & $42(6.4)$ & $8(11.3)$ \\
Difficult weaning & $47(6.3)$ & $43(6.6)$ & $3(4.2)$ \\
Chronic critical illness & $33(4.5)$ & $33(5.0)$ & NA \\
Prolonged ventilatory support/dependence & $22(3.0)$ & $17(2.6)$ & $4(5.6)$ \\
Chronic ventilation & $18(2.4)$ & $13(2.0)$ & $4(5.6)$ \\
Inability/failure to wean & $17(2.3)$ & $15(2.3)$ & $2(2.8)$ \\
Prolonged weaning & $13(1.8)$ & $13(2.0)$ & NA \\
Prolonged acute mechanical ventilation & $12(1.6)$ & $11(1.7)$ & $1(1.4)$ \\
Prolonged intubation & $11(1.5)$ & $7(1.1)$ & $4(5.6)$ \\
Extended ventilation or extended weaning & $3(0.4)$ & $3(0.5)$ & NA \\
Other $\dagger$ & $6(0.8)$ & $6(0.9)$ & NA
\end{tabular}

Results are no. (\%). Separate data are not shown for the 10 studies that reported on both an adult and pediatric population.

* Some studies used multiple terms to refer to the study cohort.

$\dagger$ Other include: long-term weaning, late extubation, delayed extubation, mechanical ventilation after hospital discharge, ineffective weaning, prolonged ventilatory failure. $\mathrm{NA}=$ not applicable

to 1 month; 39 (15.4\%) of those using the term PMV to describe the cohort (Table 4). The NAMDRC recommended criterion of $\geq 21 \mathrm{~d}$ was used by only 12 studies (2.9\%): 7 after 2005 and 5 before. The use of $\geq 21 \mathrm{~d}$ to 1 month was most common in studies from Asia (18 of $60,30 \%)$, in particular Taiwan (15 of 32, 46.9\%), and least common in studies from the United Kingdom and Europe (6 of 121, 5\%). For studies describing surgical cohorts, 20 of $66(30.3 \%)$ required a minimum duration of ventilation of $\geq 24 \mathrm{~h}$ for inclusion in the cohort, with $\geq 15 \mathrm{~d}$ being the maximum duration used by a study for participant inclusion. Other commonly used definitional criteria for PMV cohorts were the presence of a tracheostomy (81 studies, 19.4\%), admission to a specialized unit (61 studies, $14.6 \%$ ), and failure to wean (32 studies, $7.7 \%$ ) (Table 5).

\section{Rationales for Cohort Terms}

Of the 419 studies, 237 (56.6\%) gave no reason or rationale for the cohort term or the definitional criteria selected; 97 studies (23.2\%) indicated that it was specific to the admission criteria of the participating unit(s). Only 28 studies $(6.7 \%)$ referred to a consensus definition despite 185 (44\%) of included studies being published after the 2005 NAMDRC consensus definition. A further 27 (6.4\%) referred to criteria associated with diagnosis-related groupings, ICD, or other local database coding. Eleven studies (2.6\%) cited clinical relevance or local practices. Other rationales included use in previous studies $(8,1.9 \%)$, 
Table 3. Terms Used to Describe Study Cohorts by Year

\begin{tabular}{|c|c|c|c|c|c|c|c|}
\hline Cohort & $\begin{array}{c}1992-1994 \\
(\text { no. }=42)\end{array}$ & $\begin{array}{l}1995-1997 \\
(\text { no. }=79)\end{array}$ & $\begin{array}{l}1998-2000 \\
(\text { no. }=97)\end{array}$ & $\begin{array}{c}2001-2003 \\
\text { (no. }=94)\end{array}$ & $\begin{array}{l}2004-2006 \\
(\text { no. }=140)\end{array}$ & $\begin{array}{l}2007-2009 \\
(\text { no. }=157)\end{array}$ & $\begin{array}{l}2010-2013 \\
\text { (no. }=123 \text { ) }\end{array}$ \\
\hline PMV & $14(33.3)$ & $19(24.1)$ & $23(23.7)$ & $35(37.2)$ & $51(36.4)$ & $61(38.9)$ & $47(38.2)$ \\
\hline Long-term mechanical ventilation & $6(14.2)$ & $11(13.9)$ & $13(13.4)$ & $14(14.9)$ & $13(9.3)$ & $10(6.4)$ & $9(7.3)$ \\
\hline Ventilator dependence & $5(11.9)$ & $13(16.5)$ & $12(12.4)$ & $5(5.3)$ & $3(2.1)$ & $9(5.7)$ & $3(2.4)$ \\
\hline Admission criteria & $3(7.1)$ & $12(15.2)$ & $12(12.4)$ & $15(16.0)$ & $22(15.7)$ & $22(14.0)$ & $20(16.3)$ \\
\hline Tracheostomy & $3(7.1)$ & $7(8.9)$ & $12(12.4)$ & $8(8.5)$ & $12(8.6)$ & $15(9.6)$ & $10(8.1)$ \\
\hline Prolonged ventilation & $2(4.8)$ & $5(6.3)$ & $1(1.0)$ & $5(5.3)$ & $1(0.7)$ & $6(3.8)$ & $2(1.6)$ \\
\hline Chronic ventilation & $2(4.8)$ & $1(1.3)$ & $4(4.1)$ & $1(1.1)$ & $3(2.1)$ & $2(1.3)$ & $3(2.4)$ \\
\hline Difficult weaning & $2(4.8)$ & $5(6.3)$ & $8(8.2)$ & $6(6.4)$ & $7(5.0)$ & $5(3.2)$ & $14(11.4)$ \\
\hline Chronic critical illness & $1(2.4)$ & $2(2.5)$ & $5(5.2)$ & $1(1.1)$ & $9(6.4)$ & $10(6.4)$ & $5(4.1)$ \\
\hline Inability/failure to wean & NA & $3(3.8)$ & $2(2.1)$ & $1(1.1)$ & $4(2.9)$ & $5(3.2)$ & NA \\
\hline Prolonged weaning & NA & NA & $1(1.0)$ & $1(1.1)$ & $5(3.6)$ & $1(0.6)$ & $5(4.1)$ \\
\hline Prolong intubation & NA & NA & NA & $2(2.1)$ & $5(3.6)$ & $2(1.3)$ & $2(1.6)$ \\
\hline PAMV & NA & NA & $1(1.0)$ & NA & $1(0.7)$ & $7(4.5)$ & $3(2.4)$ \\
\hline Extend ventilation or weaning & $1(2.4)$ & NA & NA & NA & $1(0.7)$ & $1(0.6)$ & NA \\
\hline Other & $2(2.4)$ & $1(1.3)$ & NA & NA & $2(1.4)$ & $1(1.3)$ & NA \\
\hline
\end{tabular}

Results are no. (\%). An additional 8 studies were included published between 1980 and 1991. Of these 3 used PMV, 2 ventilator dependence, and 1 each used admission criteria, chronic ventilation, and failure to wean.

$\mathrm{PMV}=$ prolonged mechanical ventilation

$\mathrm{NA}=$ not applicable

$\mathrm{PAMV}=$ prolonged acute mechanical ventilation

Table 4. Minimum Mechanical Ventilation Duration for Cohort Inclusion

\begin{tabular}{|c|c|c|c|c|}
\hline Minimum Duration & $\begin{array}{l}\text { All Studies } \\
(\text { no. }=419)\end{array}$ & $\begin{array}{c}\text { PMV* }^{*} \\
(\text { no. }=253)\end{array}$ & $\begin{array}{c}\text { Unit } \\
\text { Admission } \\
\text { Criteria* } \\
\text { (no. }=107)\end{array}$ & $\begin{array}{c}\text { Long-Term } \\
\text { Mechanical } \\
\text { Ventilation* } \\
\text { (no. }=79 \text { ) }\end{array}$ \\
\hline Not stated & $137(32.7)$ & $71(28.1)$ & $49(45.8)$ & $26(32.9)$ \\
\hline$>1 \mathrm{y}$ & $2(0.5)$ & NA & NA & $2(2.5)$ \\
\hline$>1$ month to $<1 \mathrm{y}$ & $8(1.9)$ & $1(0.4)$ & $4(3.8)$ & $6(7.6)$ \\
\hline $21.0 \mathrm{~d}$ to $1 \mathrm{month}$ & $53(12.6)$ & $39(15.4)$ & $29(27.1)$ & $5(6.3)$ \\
\hline $14.1-20.9 \mathrm{~d}$ & $31(7.4)$ & $23(9.1)$ & $18(16.8)$ & $4(5.1)$ \\
\hline $7.1-14 \mathrm{~d}$ & $48(11.5)$ & $19(7.5)$ & $5(4.7)$ & $11(13.9)$ \\
\hline $48.1 \mathrm{~h}$ to $7 \mathrm{~d}$ & $109(26.0)$ & $71(28.1)$ & $1(1.0)$ & 25 (31.6) \\
\hline $24.1-48 \mathrm{~h}$ & $23(5.5)$ & $21(8.3)$ & NA & $2(2.5)$ \\
\hline $5.1-24 \mathrm{~h}$ & $8(1.9)$ & $8(3.2)$ & NA & NA \\
\hline \multicolumn{5}{|c|}{$\begin{array}{l}\text { Results are no. }(\%) \text {. Values may sum to more than } 100 \% \text { due to rounding. } \\
\text { * Prolonged mechanical ventilation, unit admission criteria, and long-term mechanical } \\
\text { ventilation were the most common terms used to describe study cohorts. } \\
\text { PMV = prolonged mechanical ventilation } \\
\text { NA = not applicable }\end{array}$} \\
\hline
\end{tabular}

the median duration of ventilation of the study cohort $(5,1.2 \%)$, and use as an indicator of transition from acute to chronic care $(4,0.9 \%)$ (2 studies reported miscellaneous reasons).

\section{Reported Outcomes}

There were 28 distinct outcomes reported by $\geq 5$ studies. The most commonly reported study outcomes were length of stay $(258,61.6 \%)$, mortality $(228,54.4 \%)$, and
Table 5. Definitional Criteria of Terms Used for Study Cohorts

\begin{tabular}{lccc}
\hline \hline \multicolumn{1}{c}{ Definitional Criteria } & $\begin{array}{r}\text { All Studies } \\
\text { (no. = 728) }\end{array}$ & $\begin{array}{c}\text { PMV } \\
\text { (no. }=417)\end{array}$ & $\begin{array}{c}\text { Long-Term } \\
\text { Mechanical } \\
\text { Ventilation } \\
\text { (no. = 154) }\end{array}$ \\
\hline $\begin{array}{l}\text { Duration of mechanical ventilation } \\
\text { Tracheostomy }\end{array}$ & $282(38.7)$ & $182(43.6)$ & $53(34.4)$ \\
Unit admission criteria & $141(19.4)$ & $81(19.4)$ & $28(18.2)$ \\
Failure to wean & $107(14.7)$ & $61(14.6)$ & $21(13.6)$ \\
Medical stability & $81(11.1)$ & $32(7.7)$ & $22(14.2)$ \\
Potential to wean & $32(4.4)$ & $16(3.8)$ & $10(6.5)$ \\
Database coding & $22(3.0)$ & $11(2.6)$ & $5(3.2)$ \\
Ventilator-dependent & $20(2.7)$ & $8(1.9)$ & $2(1.3)$ \\
Not defined* & $19(2.6)$ & $12(2.9)$ & $6(3.9)$ \\
Other & $18(2.5)$ & $8(1.9)$ & $7(4.5)$ \\
& $6(0.8)$ & $6(1.4)$ & NA \\
Results are no. (\%). & & & \\
* No descriptive criteria provided for the cohort term used. & & \\
PMV = prolonged mechanical ventilation & & & \\
NA = not applicable & & & \\
&
\end{tabular}

duration of mechanical ventilation $(142,33.9 \%)$ (Table 6). The rate of weaning and/or extubation success was a reported outcome in 119 studies $(28.4 \%)$ and was variably defined as $>6 \mathrm{~h}(1,0.8 \%), 24 \mathrm{~h}(9,7.6 \%), 48 \mathrm{~h}(20$, $16.8 \%), 72 \mathrm{~h}(5,4.2 \%), 5 \mathrm{~d}(1,0.8 \%), 7 \mathrm{~d}(18,15.1 \%)$, $14 \mathrm{~d}(1,0.8 \%)$, or $28 \mathrm{~d}(1,0.8 \%)$ of spontaneous breathing without mechanical ventilation. A further 26 studies $(21.8 \%)$ considered successful weaning as spontaneous breathing without mechanical ventilation at unit or hospital discharge (31 studies [26.1\%] did not provide a definition). However, no study reported on the number of days 
Table 6. Outcomes Reported by Included Studies

\begin{tabular}{lc}
\hline \hline \multicolumn{1}{c}{ Reported Outcomes (419 studies) } & no. (\%) \\
\hline Unit or hospital length of stay & $258(61.6)$ \\
Unit or hospital mortality & $228(54.4)$ \\
Duration of ventilation & $142(33.9)$ \\
ICU or ETT/tracheostomy complications & $124(29.6)$ \\
Rate of weaning/extubation success & $119(28.4)$ \\
Discharge disposition & $85(20.3)$ \\
6-month to 1-y survival & $76(18.1)$ \\
Functional status & $55(13.1)$ \\
Predictors of PMV & $54(12.9)$ \\
Tracheostomy rate or duration & $54(12.9)$ \\
Cost & $50(11.9)$ \\
Ventilator/respiratory/hemodynamic parameters & $48(11.5)$ \\
Decannulation & $38(9.1)$ \\
Prevalence or incidence of PMV (based on study & $37(8.8)$ \\
$\quad$ definition) & \\
Health-related quality of life & $34(8.1)$ \\
Predictors of weaning or extubation success & $34(8.1)$ \\
Ventilator-associated pneumonia & $32(7.6)$ \\
Duration of weaning & $29(6.9)$ \\
$\geq 2-5$ y survival & $25(6.0)$ \\
Predictors of survival or mortality & $23(5.5)$ \\
Re-intubation & $22(5.3)$ \\
ICU or hospital readmission or admission & $22(5.2)$ \\
Time to tracheostomy & $17(4.1)$ \\
Psychological outcomes (patient or caregiver) & $16(3.8)$ \\
Post-discharge survival $<6$ months & $16(3.8)$ \\
Need for home ventilation & $8(1.9)$ \\
Patient experience & $7(1.7)$ \\
Ventilator-free days & $5(1.2)$ \\
Other & $143(34.1)$ \\
\hline ETT = endotracheal tube & \\
PMV = prolonged mechanical ventilation & \\
\hline & \\
\hline
\end{tabular}

or hours between discontinuation and discharge. Only 8 studies $(6.7 \%)$ commented on inclusion of exclusion of noninvasive ventilation after discontinuation of invasive support.

\section{Discussion}

In this scoping review, we identified substantial variation in the application and definition of terms a priori hypothesized to describe mechanically ventilated subjects no longer in the acute phase of mechanical ventilation. Duration of mechanical ventilation was a common defining criterion; however, there was lack of agreement across included studies as to the number of consecutive days (or hours) that patients should require mechanical ventilation to meet cohort inclusion criteria. More than half of the included studies did not provide a rationale for their chosen definitional criteria of cohort terms used, meaning that the reasoning behind selection of these terms and their criteria was unclear. Inclusion of a large number of studies with heterogeneous study designs and study objectives resulted in the identification of numerous reported study outcomes. Additionally, we identified variability in the criteria used to define weaning and/or extubation success, specifically the duration of monitoring subsequent to liberation from mechanical ventilation during which the subject did not require further invasive or noninvasive support.

Some of the identified heterogeneity in the duration of ventilation used as definitional criteria for subject cohorts may be due to characteristics of the study region. For example, use of $\geq 21 \mathrm{~d}$ was most common in Asian countries, particularly Taiwan, where this criterion is used to step patients down to a lower level of care. ${ }^{13}$ Twenty-one days is also used as a trigger for transfer to long-term acute care in the United States ${ }^{14}$; however, only 17 long-term acute care studies from 187 United States studies were identified in this review. The duration of mechanical ventilation used as a defining criterion was also influenced by inclusion of surgical only versus a mixed study population. The longest duration used in studies of surgical subjects was $\geq 15 \mathrm{~d}$ compared with a maximum of $>1 \mathrm{y}$ in heterogeneous cohorts. Furthermore, the inclusion of studies using various data sources (direct observation vs administrative databases) may have generated heterogeneity. Data collection from an administrative database requires the use of codes, such as the ICD code 96.72 indicative of $\geq 96 \mathrm{~h}$ of mechanical ventilation, to identify a patient population, whereas prospective studies can use any criteria considered appropriate by the investigator team.

There is little doubt that there is a distinct cohort of relatively low-volume, high-cost, and poor outcome patients requiring mechanical ventilation for longer than the average ICU patient. ${ }^{15-19}$ In 1989, Wagner et al ${ }^{20}$ identified that $6 \%$ of a cohort of nearly 4,000 ICU subjects were ventilated for $\geq 7 \mathrm{~d}$ and consumed $37 \%$ of ICU costs, suggesting that this is not necessarily a new phenomenon solely due to advances in technology or worsening population comorbidity. However, our data suggest that we are far from understanding whether study cohorts are referring to similar patient phenotypes within or across studies and far from establishing consensus on how to define this cohort. Using terms such as chronic or persistent critical illness, several studies have documented a syndrome of persistent organ dysfunction characterized by profound weakness and extreme symptom burden. ${ }^{21}$ Such terms may have merit when trying to distinguish subject cohorts within the spectrum of critical illness; however, while also suffering from lack of consensus, some authors believe this term encompasses patients without a concomitant prolonged need for mechanical ventilation. Conversely, patients such as those with established neuromuscular dis- 
ease may require prolonged to indefinite mechanical ventilation and not meet other definitional requirements of chronic critical illness. ${ }^{22}$

Lack of consistency as to the number of consecutive days (or hours for surgical patients) used as definitional criteria suggests that this may be a rather arbitrary marker and may not be the best criterion to identify transition from acute to PMV and a concomitant review of goals of care. Indeed, using Delphi methods and a 38-member expert panel to establish the criteria that should define the transition from acute care to PMV, our group identified that the number of consecutive days of mechanical ventilation was one of 6 (out of 20) defining criteria that did not gain consensus. ${ }^{23}$ Preferred criteria were patient stability from a physiological perspective, repeated unsuccessful attempts at weaning, and the patient's wishes to remain ventilated. These criteria reflect transition from the acute phase of critical illness and an estimation of weaning difficulty as reflected in the simple, difficult, and prolonged weaning classifications proposed in 2007.24 These weaning classifications may be more useful than terms such as PMV not only because they incorporate an element of weaning difficulty but also because they provide an objective marker that weaning attempts have been commenced. What is missing from these classifications, warranting further consideration, is when to classify a patient as unweanable.

We found that definition of the time period in which determination of weaning and/or extubation success occurred was highly variable, ranging from $6 \mathrm{~h}$ to $28 \mathrm{~d}$. The NAMDRC definition suggests that PMV patients should only be considered successfully weaned when able to maintain spontaneous breathing without invasive or noninvasive ventilatory support for a minimum of $7 \mathrm{~d} .{ }^{8}$ Rationales for monitoring over $7 \mathrm{~d}$ for the need to reestablish mechanical ventilation included the potential for slower recovery of the respiratory system and the likelihood of more chronic comorbidities in this patient population. Additionally, some authors have suggested that the need for reestablishment of mechanical ventilation after $3 \mathrm{~d}$ is most likely due to a new or unrelated process. ${ }^{25}$ However, from a patient and health-care system provider perspective, no further requirement for mechanical ventilation enabling discharge from the admitting unit is a more useful definition of weaning and/or extubation success because it demonstrates recovery and the ability to transition to a loweracuity and therefore lower-cost care location.

Few studies included in this scoping review commented on the inclusion of noninvasive ventilation after discontinuation of invasive support when defining weaning success. The role of noninvasive ventilation is an important element for consideration for this definition, ${ }^{24}$ particularly in view of increased utilization in recent years. ${ }^{26} \mathrm{~A} \mathrm{Co}$ chrane systematic review ${ }^{27}$ found that the use of noninva- sive ventilation as a weaning strategy to enable extubation for subjects with the potential to wean, but not yet able to tolerate mechanical ventilation discontinuation, demonstrated decreased weaning failure, mortality, ventilatorassociated pneumonia, ventilation duration, and ICU length of stay compared with weaning strategies that did not include noninvasive ventilation. Failure to consider the use of noninvasive ventilation after extubation when pooling data from studies that do or do not use an early extubation to noninvasive ventilation approach will produce inaccurate estimates of weaning success.

We identified 39 distinct study outcomes reported by $\geq 3$ included studies, with stay, mortality, and mechanical ventilation duration described by over one third of studies. Previously, our group has identified substantial variation in the selection and definition of outcomes among trials of interventions hypothesized to influence mechanical ventilation duration. ${ }^{28}$ Initiatives such as the Core Outcome Measures in Effectiveness Trials (COMET) group aim to facilitate the development and application of agreed standardized sets of outcomes, referred to as core outcome sets. ${ }^{29}$ Numerous critical care professional societies have called for standardization in the reporting of study end points and a standard set of outcome measures with several core outcome set development projects related to critical care under way. ${ }^{30}$ However, such initiatives are relatively recent. Our data can be used to inform such a project that can then be used in future studies of patients experiencing PMV. Without strategies to gain consensus, known variation in the selection and measurement of outcomes of studies recruiting mechanically ventilated patients combined with variation in subject cohort definitions, as identified in this scoping review, will continue to drive inconsistency and limit interpretation of study findings.

Classification of homogeneous cohorts of mechanically ventilated subjects experiencing critical illness using clear definitional criteria is important. Prognostication, care goal setting, implementation of effective therapies, or conversely conversations around limitation of therapy may be limited due to a failure or delay in recognizing patient transition from acute care to PMV.23,31 Additionally, clear definitions are required for successful conduct of further research, including enrollment of subjects with a similar phenotype into clinical trials, epidemiological studies, and meta-analyses. ${ }^{32,33}$ Our data suggest that further consensus work is required to classify these cohorts, considering defining features in addition to the duration of mechanical ventilation. Such consensus work is likely to result in a set of terms as opposed to a single term to describe the patient spectrum.

\section{Strengths and Limitations}

To our knowledge, this is the first scoping review to use rigorous and a priori developed methods to systematically 
quantify cohort terms and their definitional criteria hypothesized to describe subjects no longer in the acute phase of mechanical ventilation. Our scoping review has the following limitations. First, our search only extends to March 2013 and therefore may not reflect terms and definitions in most recent publications. However, we included $>400$ studies and did not detect a demonstrable shift in terms used and their definitions over time, particularly after publication of the 2005 NAMDRC definition. ${ }^{8}$ We therefore believe that expanding the search to 2016 would not substantially influence our results and conclusions. Second, for pragmatic reasons, we limited our inclusion criteria to studies published in English, meaning that our findings may not reflect the use of cohort terms in studies published in other languages.

\section{Summary}

We identified substantial variation exists in the terminology and definitional criteria for cohorts of subjects receiving mechanical ventilation as well as reported study outcomes. Few studies provided a rationale for selection of cohort terms and their definitional criteria, making it difficult to draw conclusions as to the reasons for this substantial variation. Standardization of terminology and definitional criteria is required for study data to be maximally informative for clinical decision making and future research.

\section{REFERENCES}

1. Sansone GR, Frengley JD, Vecchione JJ, Manogaram MG, Kaner RJ. Relationship of the duration of ventilator support to successful weaning and other clinical outcomes in 437 prolonged mechanical ventilation patients. J Intensive Care Med 2017;32(4):283-291.

2. Jeong BH, Ko MG, Nam J, Yoo H, Chung CR, Suh GY, Jeon K. Differences in clinical outcomes according to weaning classifications in medical intensive care units. PLoS One 2015;10(4):e0122810.

3. Cislaghi F, Condemi AM, Corona A. Predictors of prolonged mechanical ventilation in a cohort of 3,269 CABG patients. Minerva Anestesiol 2007;73(12):615-621.

4. Petrou A, Lagos N, Arnaoutoglou E, Tzimas P, Krikonis K, Papadopoulos G. Five classes Euroscore modification improves accuracy of prediction of postoperative mortality and possibly the length of mechanical ventilation of cardiac surgery patients. J Cardiovasc Surg 2015;56(6):905-912.

5. Figueroa-Casas JB, Dwivedi AK, Connery SM, Quansah R, Ellerbrook L, Galvis J. Predictive models of prolonged mechanical ventilation yield moderate accuracy. J Crit Care 2015;30(3):502-505.

6. Carson SS, Kahn JM, Hough CL, Seeley EJ, White DB, Douglas IS, et al. A multicenter mortality prediction model for patients receiving prolonged mechanical ventilation. Crit Care Med 2012;40(4):11711176.

7. Hough CL, Caldwell ES, Cox CE, Douglas IS, Kahn JM, et al. Development and validation of a mortality prediction model for patients receiving 14 days of mechanical ventilation. Crit Care Med 2015;43(11):2339-2345.

8. MacIntyre NR, Epstein SK, Carson S, Scheinhorn D, Christopher K, Muldoon S, National Association for Medical Direction of Respiratory Care. Management of patients requiring prolonged mechanical ventilation: report of a NAMDRC consensus conference. Chest 2005; 128(6):3937-3954.

9. Bice T, Nelson JE, Carson SS. To trach or not to trach: uncertainty in the care of the chronically critically ill. Semin Respir Crit Care Med 2015;36(6):851-858.

10. Zilberberg MD, de Wit M, Pirone JR, Shorr AF. Growth in adult prolonged acute mechanical ventilation: implications for healthcare delivery. Crit Care Med 2008;36(5):1451-1455.

11. Cox CE, Carson SS, Lindquist JH, Olsen MK, Govert JA, Chelluri L. Differences in one-year health outcomes and resource utilization by definition of prolonged mechanical ventilation: a prospective cohort study. Crit Care 2007;11(1):R9.

12. Glasziou PP, Sanders SL. Investigating causes of heterogeneity in systematic reviews. Stat Med 2002;21(11):1503-1511.

13. Hung MC, Lu HM, Chen L, Hu FC, Chan SY, Yan YH, et al. Life expectancies and incidence rates of patients under prolonged mechanical ventilation: a population-based study during 1998 to 2007 in Taiwan. Crit Care 2011;15(2):R107.

14. Kahn JM, Benson NM, Appleby D, Carson SS, Iwashyna TJ. Longterm acute care hospital utilization after critical illness. JAMA 2010; 303(22):2253-2259.

15. Carson SS. Outcomes of prolonged mechanical ventilation. Curr Opin Crit Care 2006;12(5):405-411.

16. Lone NI, Walsh TS. Prolonged mechanical ventilation in critically ill patients: epidemiology, outcomes and modelling the potential cost consequences of establishing a regional weaning unit. Crit Care 2011; 15(2):R102.

17. Clark PA, Lettieri CJ. Clinical model for predicting prolonged mechanical ventilation. J Crit Care 2013;28(5):880.e1-7.

18. Iwashyna TJ, Hodgson CL, Pilcher D, Bailey M, van Lint A, Chavan S, Bellomo R. Timing of onset and burden of persistent critical illness in Australia and New Zealand: a retrospective, populationbased, observational study. Lancet Respir Med 2016;4(7):566-573.

19. Nabozny MJ, Rathouz PJ, Havlena JA, Kind AJ, Ehlenbach WJ, Zhao Q, et al. Trajectories and prognosis of older patients who have prolonged mechanical ventilation after high-risk surgery. Crit Care Med 2016;44(6):1091-1097.

20. Wagner DP. Economics of prolonged mechanical ventilation. Am Rev Respir Dis 1989;140(2 Pt 2):S14-S18.

21. Maguire JM, Carson SS. Strategies to combat chronic critical illness. Curr Opin Crit Care 2013;19(5):480-487.

22. Macintyre NR. Chronic critical illness: the growing challenge to health care. Respir Care 2012;57(6):1021-1027.

23. Rose L, Fowler RA, Goldstein R, Katz S, Leasa D, Pedersen C, et al. Patient transitions relevant to individuals requiring ongoing ventilatory assistance: a Delphi study. Can Respir J 2014;21(5):287-292.

24. Boles JM, Bion J, Connors A, Herridge M, Marsh B, Melot C, et al. Weaning from mechanical ventilation. Eur Respir J 2007;29(5): 10331056.

25. Epstein SK. Etiology of extubation failure and the predictive value of the rapid shallow breathing index. Am J Respir Crit Care Med 1995; 152(2):545-549.

26. Demoule A, Chevret S, Carlucci A, Kouatchet A, Jaber S, Meziani $\mathrm{F}$, et al. Changing use of noninvasive ventilation in critically ill patients: trends over 15 years in francophone countries. Intensive Care Med 2016;42(1):82-92.

27. Burns KE, Meade MO, Premji A, Adhikari NK. Noninvasive ventilation as a weaning strategy for mechanical ventilation in adults with respiratory failure: a Cochrane systematic review. CMAJ 2014; 186(3):E112-E122.

28. Blackwood B, Clarke M, McAuley DF, McGuigan PJ, Marshall JC, Rose L. How outcomes are defined in clinical trials of mechanically ventilated adults and children. Am J Respir Crit Care Med 2014; 189(8):886-893. 
29. Prinsen CA, Vohra S, Rose MR, King-Jones S, Ishaque S, Bhaloo Z, et al. Core Outcome Measures in Effectiveness Trials (COMET) initiative: protocol for an international Delphi study to achieve consensus on how to select outcome measurement instruments for outcomes included in a "core outcome set". Trials 2014;15:247.

30. Blackwood B, Marshall J, Rose L. Progress on core outcome sets for critical care research. Curr Opin Crit Care 2015;21(5):439444.
31. Carson SS. Definitions and epidemiology of the chronically critically ill. Respir Care 2012;57(6):848-856; discussion 856858.

32. Streiner D, Norman G. Health measurement scales. New York: Oxford University Press; 2008:7-17.

33. ARDS Definition Task Force, Ranieri VM, Rubenfeld GD, Thompson BTD, Caldwell E, et al. Acute respiratory distress syndrome: the Berlin Definition. JAMA 2012;307(23):2526-2533. 